\title{
Gender Determination with Ischiopubic Index and Upper Pelvic Index in Iranian Adult Radiographic Stereotypes
}

\author{
Hossein Ahmadi Kahjoogh ${ }^{1}$, Maryam Vasheghani Farahani ${ }^{2,{ }^{*},}$, Babak Shekarchi ${ }^{3}$, Beheshteh \\ Abouhamzeh (iD ${ }^{4}$ and Mahdi Isazadeh (iD) ${ }^{5}$ \\ ${ }^{1}$ Student Research Committee, Faculty of Medicine, AJA University of Medical Sciences, Tehran, Iran \\ ${ }^{2}$ Department of Forensic Medicine and Clinical Toxicology, Faculty of Medicine, AJA University of Medical Sciences, Tehran, Iran \\ ${ }^{3}$ Radiology Department, School of Medicine, AJA University of Medical Sciences, Tehran, Iran \\ ${ }^{4}$ Department of Anatomical Sciences, Faculty of Medicine, AJA University of Medical Sciences, Tehran, Iran \\ ${ }^{5}$ Student Research Committee, Faculty of Medicine, Aja University of Medical Sciences, Tehran, Iran \\ "Corresponding author: Department of Forensic Medicine and Clinical Toxicology, Faculty of Medicine, AJA University of Medical Sciences, Tehran, Iran. Email: \\ vasheghani_m@yahoo.com
}

Received 2021 February 08; Revised 2021 May 05; Accepted 2021 June 07.

\begin{abstract}
Background: Different parts of the skeletal system have been studied in different studies to determine gender. The pelvis is one of the most important skeletal components for the determination of gender and identification of humans.

objectives: The current study aimed to determine gender using the ischiopubic index and upper pelvic index in the adult population of Iran.

Methods: In this study, 140 individuals (70 male and 70 female subjects) referring to Athari Imaging Center in Tehran, Iran, for various medical reasons entered the study by giving written and oral consent using the convenience sampling method. Measurements were performed on digital anteroposterior pelvic radiographs (with standard conditions and radiographic stencil distance from the light source as $100 \mathrm{~cm}$ ). The obtained data were analyzed using SPSS software (version 22).

Results: The mean ischemic index of the whole population was $108.88 \pm 13.75$. The difference in the ischiopubic index between male and female subjects was significant $(\mathrm{P}<0.05)$. The mean upper pelvic index of the whole study population was $81.70 \pm 10.09$; however, the difference in the upper pelvic index between the two groups of male and female subjects was not significant $(\mathrm{P}<0.05)$. Conclusions: The pelvic ischemic index in Iranian women is higher than that reported for men. If the ischiopubic index is higher than 103 , with $93 \%$ sensitivity and $73 \%$ specificity, it would be female. According to the study of graphs, if there is a special identity for diagnosis, there will be the possibility to match the graph before the death of the individual with the graph taken from skeletal remains.
\end{abstract}

Keywords: Gender Determination, Radiography, Ischiopubic Index, Upper Pelvic Index

\section{Background}

One of the main factors in forensic identification is gender determination (1). The exclusive morphology of the human bone and their gender differences are of interest to forensic physicians, anthropologists, and anatomists examining them for a variety of reasons (2-5). Different parts of the skeletal system have been studied in different studies to determine gender. The pelvis is one of the most important skeletal components for the determination of gender and identification of humans (6). Other bones can also be used to determine genders, such as the skull, long bones with one epiphysis and one metaphysis, paranasal sinuses, foramen magnum, maxillary sinus, and teeth (7-10). Studies showed that gender can be determined with $80 \%$ con- fidence using the skull, 90\% confidence using head and mandible, and $80 \%$ confidence using pelvis bone (11). The hip bone is an appropriate bone for gender determination because it shows the general differences between male and female genders and has a great adaptation of female hip bone for giving birth (12).

According to a study conducted by Washburn (2), the use of pelvic features is the most successful method for the determination of gender in different communities. Radiography can help determine gender by providing accurate dimensions (13). The anthropometric dimensions of the different bones of the body in each race and geographical area are unique; therefore, regional measurements should be made for each region of the world (14). A limited number of studies have been performed on pelvic bone in Iran. 
Furthermore, a codified table of anthropometric dimensions of all bones of the body, including the pelvis in men and women, is necessary to use in gender determination in Iran.

\section{Objectives}

The current study aimed to determine the gender using the ischiopubic index and upper pelvic index in Iranian adult radiographic stereotypes.

\section{Methods}

This descriptive cross-sectional analytical study was conducted at AJA University of Medical Sciences, Tehran, Iran, during 2016 and 2017. In this study, 140 individuals (70 male and 70 female subjects) referring to Athari Imaging Center in Tehran for various medical reasons entered the study by giving written and oral consent using the convenience sampling method. The inclusion criteria were referral for pelvic imaging, age of over 18 years, and Iranian nationality. The exclusion criteria were dissatisfaction, bone abnormalities, pelvic fractures, and underlying diseases. Measurements were performed on digital anteroposterior pelvic radiographs (with standard conditions and radiographic stencil distance from the light source as $100 \mathrm{~cm}$ ). The ischiopubic index was calculated by dividing the measured length of the pubic bone by the length of the ischial bone in millimeters multiplied by 100 (15) using the PACS software (version 2020).

The distance from the central point of the acetabular cavity to the innermost point of the anterior edge of the symphysis pubis is called the length of the pubis, and the distance from the central point of the acetabular cavity to the most distal point in the trunk of the ischium bone is called the ischium length (15). The measurements were independently performed by two individuals to avoid measurement errors. The obtained data were analyzed using SPSS software (version 22). In addition, a receiver operating characteristic (ROC) curve was used to evaluate the differential power of the ischiopubic index and upper pelvic index in gender differentiation in the whole population and age groups. In this study, the confidentiality of patients' information was ensured, and it was published without mentioning the names. The patients could withdraw from the study at any time. Moreover, the participation in this study bore no costs, and all costs were paid by the researchers. The present study did not interfere with the treatment of patients.

\section{Results}

The study population were within the age range of 18 to a maximum of 70 years divided into three age groups, namely 18 - $34(\mathrm{n}=29 ; 20.7 \%), 35-49(\mathrm{n}=36 ; 25.7 \%)$, and over $50(\mathrm{n}=75 ; 53.6 \%)$ years. The mean ischemic index of the whole population was $108.88 \pm 13.75$, with a minimum of 84.80 and a maximum of 153.33 . The mean ischiopubic index of the male group was $99.59 \pm 7.89$, with a minimum of 84.80 and a maximum of 120.06 . The mean ischiopubic index of the female group was $118.16 \pm 11.95$, with a minimum of 93.42 and a maximum of 153.33. In all the age groups, the difference in the ischiopubic index between male and female subjects was significant $(\mathrm{P}<0.05$; Table 1$)$.

The mean upper pelvic opening index of the whole study population was $81.70 \pm 10.09$. The mean values of the upper pelvic opening index were calculated at $80.24 \pm$ 9.49 in men and $83.16 \pm 10.53$ in women. The results of the Mann-Whitney U test showed that this difference was not significant $(\mathrm{P}<0.05)$. The difference in the upper pelvic index in different age groups among male and female subjects was not significant $(\mathrm{P}<0.05$; Table 2$)$.

The ROC curve was used to evaluate the differentiating power of the ischiopubic index in gender differentiation in the whole population and age groups. The area under the curve in the whole population for gender differentiation was $90 \%$ (Figure 1). The areas under the ROC curve for gender differentiation were 94,93 , and $89 \%$ in the age groups of 18 -34, 35 - 50, and over 50 years, respectively (Table 3 ).

The ROC curve was used to evaluate the differentiating power of the upper pelvic index (brim) in gender differentiation in the whole population and age groups. The area under the curve in the whole population for gender differentiation was $414 \%$ (Figure 2). The areas under the curve for gender differentiation were 377,413 , and $457 \%$ in the age groups of 18 - 34, 35 - 49, and over 50 years, respectively (Table 4$)$.

To obtain the sensitivity and specificity of the ischemic index for differentiation between the two genders, the demarking point was determined using the ROC curve (Table 5).

\section{Discussion}

Other studies in Iran regarding gender determination have been performed using the ischiopubic index; however, for the achievement of comprehensive and general results, it is required to carry out further studies, such as the present study, to generalize the results to the whole Iranian society. Although the non-metric measurements of the skeleton were initially used to determine gender in the literature, scientific metric measurements were later used. 


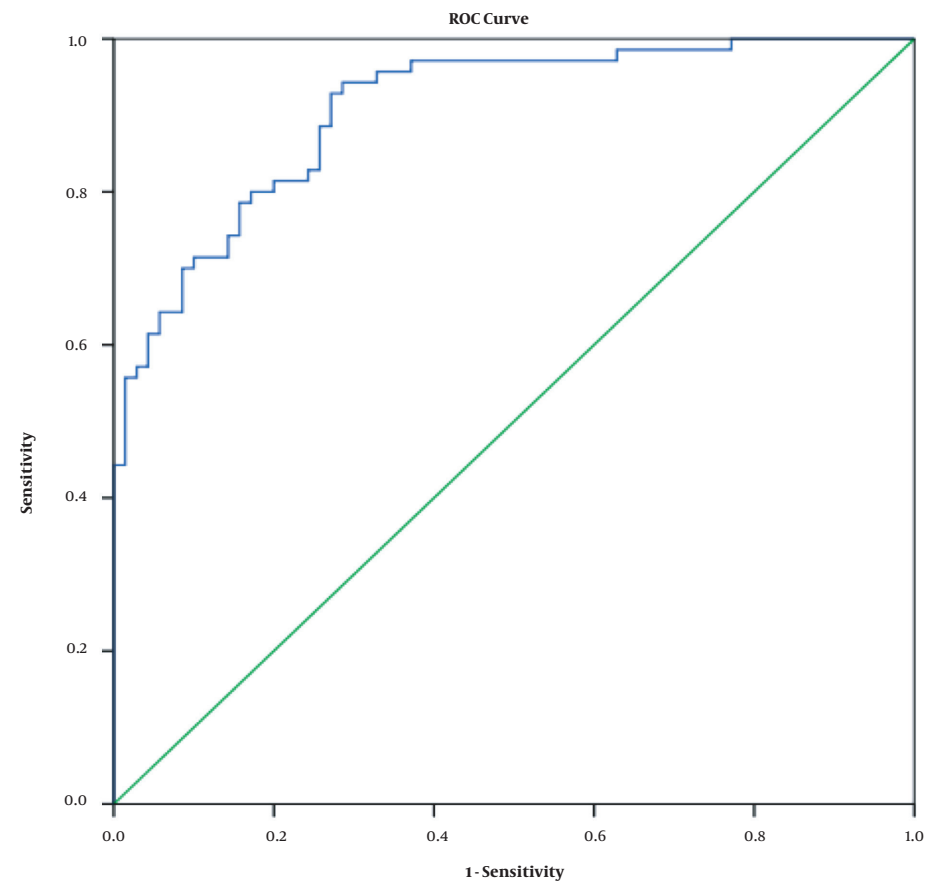

Figure 1. Receiver operating characteristic curve for the ischiopubic index in the whole study population

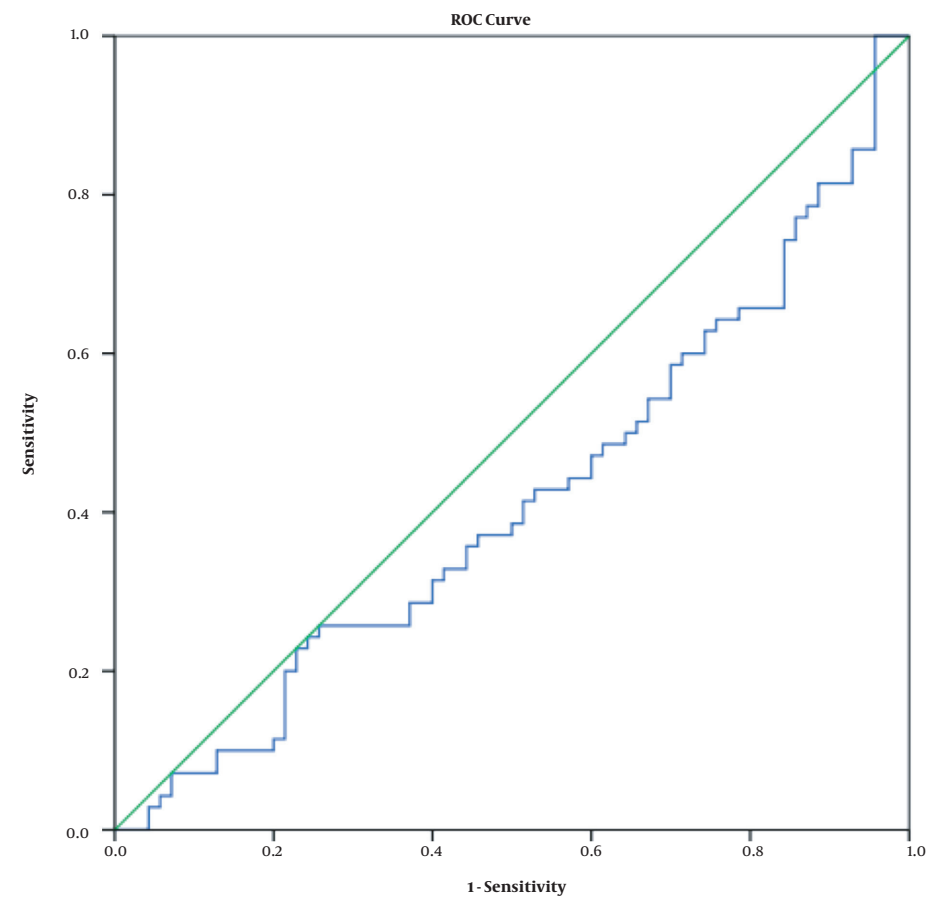

Figure 2. Receiver operating characteristic curve of brim index in the whole study population 


\begin{tabular}{|c|c|c|c|c|c|}
\hline Age $(y) /$ Gender & Mean & Standard Deviation & Maximum & Minimum & P-Value $^{a}$ \\
\hline 18 - 34 & & & & & 0.00 \\
\hline Male & 100.73 & 6.18 & 115.77 & 91.86 & \\
\hline Female & 119.27 & 11.00 & 142.41 & 102.32 & \\
\hline $35-49$ & & & & & 0.00 \\
\hline Male & 102.52 & 7.74 & 114.66 & 90.11 & \\
\hline Female & 120.64 & 10.82 & 153.33 & 104.61 & \\
\hline Total & 113.097 & 13.15 & 153.33 & 90.11 & \\
\hline Above 50 & & & & & 0.00 \\
\hline Female & 116.40 & 12.88 & 149.02 & 93.42 & \\
\hline Total & 107.04 & 14.22 & 149.02 & 84.80 & \\
\hline
\end{tabular}

${ }^{\mathrm{a}} \mathrm{P}<0.05$ considered statistically significant.

\begin{tabular}{|c|c|c|c|c|c|}
\hline Age $(y) /$ Gender & Mean & Standard Deviation & Maximum & Minimum & P-Value \\
\hline $18-34$ & & & & & 0.26 \\
\hline Male & 84.71 & 9.00 & 102.83 & 68.44 & \\
\hline Female & 90.41 & 11.86 & 115.65 & 73.42 & \\
\hline Total & 87.07 & 10.47 & 115.65 & 68.44 & \\
\hline $35-49$ & & & & & 0.37 \\
\hline Male & 82.65 & 12.70 & 104.73 & 65.91 & \\
\hline Female & 85.70 & 6.56 & 96.22 & 70.26 & \\
\hline Total & 84.43 & 9.56 & 104.73 & 65.91 & \\
\hline Above 50 & & & & & 0.51 \\
\hline Male & 77.28 & 7.17 & 92.11 & 64.78 & \\
\hline Female & 79.37 & 10.48 & 113.47 & 62.79 & \\
\hline Total & 78.31 & 8.95 & 113.47 & 62.79 & \\
\hline
\end{tabular}

Table 3. Ischiopubic Index Differentiation Power in Gender Differentiation in Each Age Group and the Whole Population Using the Area Under the Receiver Operating Characteristic Curve

\begin{tabular}{llll}
\hline Age Group $(\mathbf{y})$ & Area & Standard Error & P-Value $^{\mathbf{a}}$ \\
\hline $\mathbf{1 8}-\mathbf{3 4}$ & 0.941 & 0.041 & 0.000 \\
$\mathbf{3 5 - 5 0}$ & 0.933 & 0.037 & 0.000 \\
$>\mathbf{5 0}$ & 0.892 & 0.037 & 0.000 \\
Total & 0.908 & 0.024 & 0.000 \\
\hline
\end{tabular}

${ }^{\mathrm{a}} \mathrm{P}<0.05$ considered statistically significant.

Metric measurements are preferred due to their easy reproducibility, high accuracy, and lack of special skills (16). The mean ischemic index in the present study is almost similar to the mean in a 2014 study by Ekanem et al. (15) on the La- gos population of Nigeria and a study by Baskerville (17) on the New Zealand population; however, it is different from the mean in another study (18) and a study by Haidar et al. (19) in Pakistan. Due to the similarity of the study meth- 


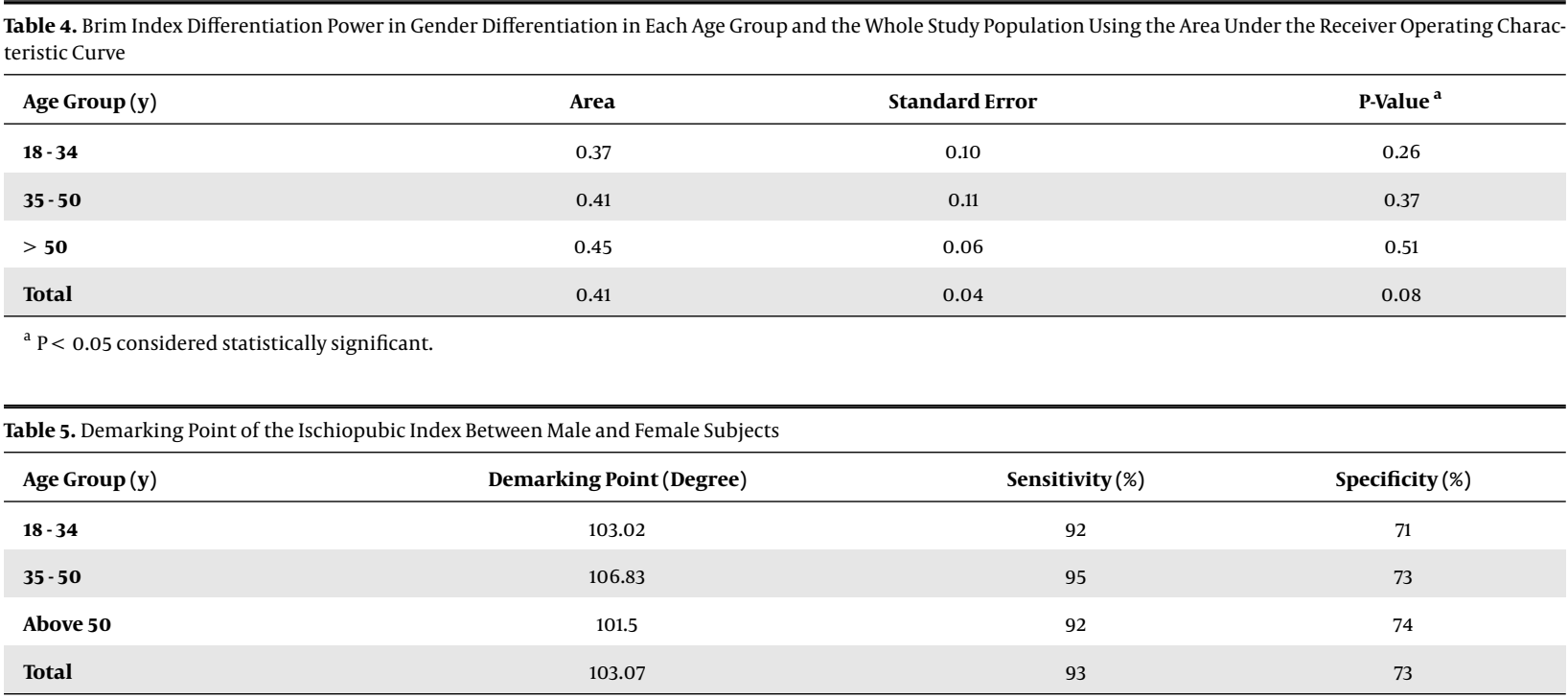

ods and measurement techniques, this differences could be due to racial and differences, regional and environmental effects, and nutrition.

The comparison of the results of the present study with the results of other studies conducted among the residents of different regions of Nigeria showed that there is a statistically significant difference in the values of the ischemic index between different ethnicities, even in a country like Nigeria. This index is higher in women than men in various studies in other countries, such as New Zealand and India, and in this respect is similar to all similar studies in Nigeria. There was a statistically significant difference in the measured values of this index among men and women of all races. In the present study, similar to previous studies, this difference is statistically significant. Furthermore, the values of the ischiopubic index are partly similar to those of the Indians and residents of Lagos State and Nigeria, which may be due to the common ancestry of these races, migration, and environmental effects.

Regarding the ischiopubic index, the highest subcurve levels in the ROC curve were in the age groups of 18 - 34 and 35 - 50 years. Moreover, the lowest sub-curve level in the ROC curve was in the age group above 50 years; however, the sub-curve level in all age groups was considered desirable to differentiate gender. The sub-curve level exists but decreases slightly with age. Regarding the upper pelvic index, as previously reported, the difference in the mean of this index between both males and females was not statistically significant. In this regard, the results of the current study are in line with the results of a study performed by Osunwoke et al. (20) in Nigeria in 2013. In addition, this index helps to differentiate genders in accidents and disas- ters but does not help to identify corpses.

Considering that this study was performed on adults, to compare the results in gender differentiation, it is suggested to perform a study on a younger age than puberty. This study was conducted on different Iranians living in Tehran. The results can be generalized to other parts of the country; however, it is recommended to perform similar studies in other parts of the country. Due to the possibility of vulnerability and loss of pelvic bone, its unavailability in skeletal remains, and observation of racial differences in bone anthropometric criteria, it is recommended to study other anthropometric pelvic indicators to determine gender.

Similar to other studies on the ischemic pelvic index, this value is higher in Iranian women than men. If the ischiopubic index is higher than 103, with 93\% sensitivity and $73 \%$ specificity, it would be female. According to the study of the graphs, if there is a special identity for diagnosis, there will be the possibility to match the graph before the death of the individual with the graph taken from skeletal remains. It is easy and affordable, and the results are very reliable. This study was performed on Iranians over 18 years of age; therefore, caution should be exercised in generalizing the results of the present study to other populations younger than puberty and direct measurements of bone.

\section{Footnotes}

Authors' Contribution: All the authors equally contributed to the writing and revision of this paper.

Conflict of Interests: All the authors declare that there is no conflict of interest. 
Ethical Approval: This study was approved by the Ethics Committee of AJA University of Medical Sciences (code: IR. AJAUMS.1399.225).

Funding/Support: This study was funded by the vicechancellor for Research and Technology of AJA University of Medical Sciences.

Informed Consent: Written and oral consent was obtained from the patients.

\section{References}

1. Khangura RK, Sircar K, Singh S, Rastogi V. Sex determination using mesiodistal dimension of permanent maxillary incisors and canines. J Forensic Dent Sci. 2011;3(2):81-5. doi: 10.4103/0975-1475.92152. [PubMed: 22408326]. [PubMed Central: PMC3296380].

2. Washburn SL. Sex differences in the pubic bone. Am J Phys Anthropol. 1948;6(2):199-207. doi: 10.1002/ajpa.1330060210. [PubMed: 18867363].

3. Washburn SL. Sex differences in the pubic bone of Bantu and Bushman. Am J Phys Anthropol. 1949;7(3):425-32. doi: 10.1002/ajpa.1330070308. [PubMed: 15406806].

4. Schulter-Ellis FP, Schmidt DJ, Hayek LA, Craig J. Determination of sex with a discriminant analysis of new pelvic bone measurements: Part I. J Forensic Sci. 1983;28(1):169-80. [PubMed: 6680735].

5. Singh S, Potturi BR. Greater sciatic notch in sex determination. J Anat. 1978;125(Pt 3):619-24. [PubMed: 640963]. [PubMed Central: PMC1235628].

6. Ahankari RS, Ambali MP. Sexual dimorphism in human sacrum in Maharshtra population. Indian J Clin Anat Physiol. 2016;3(1):91. doi: 10.5958/2394-2126.2016.00022.0.

7. Uthman AT, Al-Rawi NH, Al-Timimi JF. Evaluation of foramen mag num in gender determination using helical CT scanning. Dentomaxillofac Radiol. 2012;41(3):197-202. doi:10.1259/dmfr/21276789. [PubMed: 22116135]. [PubMed Central: PMC3520293].

8. Teke HY, Duran S, Canturk N, Canturk G. Determination of gender by measuring the size of the maxillary sinuses in computerized tomography scans. Surg Radiol Anat. 2007;29(1):9-13. doi: 10.1007/s00276006-0157-1. [PubMed: 17171233].
9. Leopold D, Novotny V. [Sex determination from the skull and parts of the hip bone]. Gegenbaurs Morphol Jahrb. 1985;131(3):277-85. German. [PubMed: 3899847].

10. Luo YC. Sex determination from the pubis by discriminant function analysis. Forensic Sci Int. 1995;74(1-2):89-98. doi: 10.1016/03790738(95)01739-6. [PubMed: 7665136].

11. Şahİner Y, YalÇin H. [Determine the gender from cranial bone by using geometric morphometric method in males and females and ramus flexure]. Atatürk Üniversitesi Vet Bil. 2007;2(4):134-42. Turkish.

12. Ekanem T, Udongwu A, Singh S. Radiographic determination of sex differences in ischiopubic index of a Nigerian population. Internet $J$ Biol Anthropol. 2009;3(2). doi: 10.5580/8c7.

13. Di Vella G, Campobasso CP, Dragone M, Introna FJ. Skeletal sex determination by scapular measurements. Boll Soc Ital Biol Sper 1994;70(12):299-305. [PubMed: 7748529].

14. Introna FJ, Di Vella G, Campobasso CP. Sex determination by discriminant analysis of patella measurements. Forensic Sci Int.1998;95(1):3945. doi: 10.1016/s0379-0738(98)00080-2. [PubMed: 9718670].

15. Ekanem TB, Akpan EJ, Mesembe OE. A study of ischiopubic index using x-ray films in Lagos State of Nigeria. Adv Anat. 2014;2014:1-4. doi $10.1155 / 2014 / 192897$.

16. Ramadan SU, Turkmen N, Dolgun NA, Gokharman D, Menezes RG, Kacar M, et al. Sex determination from measurements of the sternum and fourth rib using multislice computed tomog raphy of the chest. Forensic Sci Int. 2010;197(1-3):120 e1-5. doi: 10.1016/j.forsciint.2009.12.049. [PubMed: 20083365].

17. Baskerville RF. The ischium/pubic index for sex determination from fragmentary pelvic material in prehistoric New Zealand populations. New Zealand Journal of Archaeology. 1992;(14):159-66.

18. Attah MO, Suleiman ID, Samaila MC, Amaza DS, Ishaya HB, Balogun $\mathrm{SU}$, et al. A study of the ischiopubic index: A radiographic analysis in Maiduguri, North Eastern Nigeria. J Dent Med Sci. 2015;14(8):118-21.

19. Haider A, Kamran S, Arif M, Raouf D. Role of ischiopubic index in sex determination on pelvis x-rays. Journal of the Society of Obstetrics and Gynaecologists of Pakistan. 2019;9(4):231-4.

20. Osunwoke EA, Olotu EJ, Allison TA, Oriji CN, Mbadugha CC. The discriminant formula for the determination of sex of adults in a Nigerian population (using pelvic radiographs).J Nat Sci Res. 2013;3:176-80 